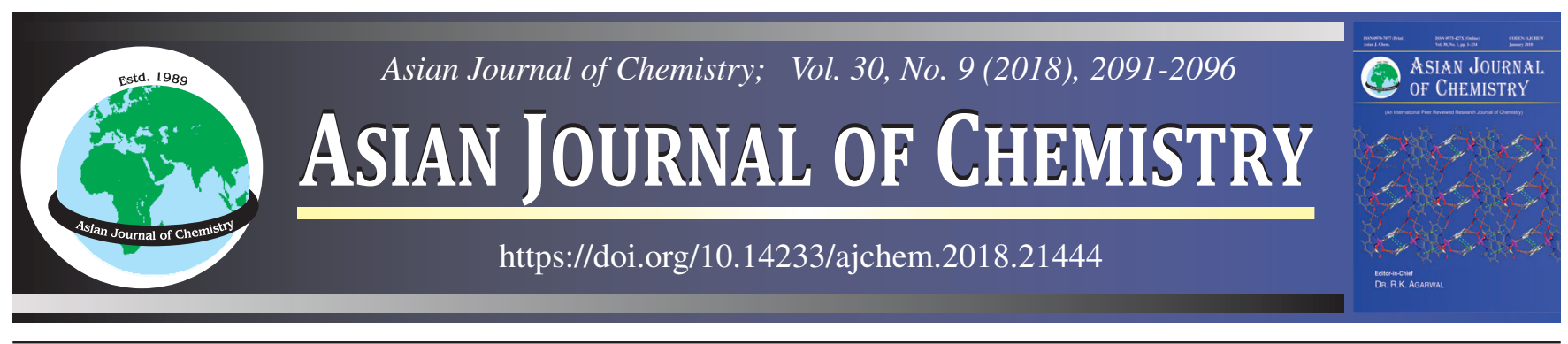

\title{
Photo-Electrochemical Water Splitting Behaviour of CdSe Quantum Dots Sensitized Ferroelectric $\mathrm{PbTiO}_{3}$ Perovskite Heterostructure
}

\author{
D. SOUMYA RANI ${ }^{1}$ and A. CYRIL ${ }^{2, *}$
}

${ }^{1}$ Department of Chemistry, Christian College, Kattakada Post, Thiruvananthapuram-695 572, India

${ }^{2}$ Post Graduate and Research Department of Chemistry, Raja Doraisingam Government Arts College, Sivaganga-630 561, India

*Corresponding author: E-mail: cyrilchemistry@gmail.com

Received: 14 May 2018;

Accepted: 14 June 2018;

Published online: 31 July 2018;

AJC-19026

\begin{abstract}
Herein, we report the photo-electrochemical water splitting of $\mathrm{CdSe}$ quantum dots sensitized $\mathrm{PbTiO}_{3}$ perovskite in a sacrificial electrolyte. TheCdSe quantum dots are synthesized via hot injection method and perovskite. The $\mathrm{PbTiO}_{3}$ is synthesized via hydrothermal synthesis procedure. The CdSe quantum dots are sensitized to $\mathrm{PbTiO}_{3}$ using mercaptopropionic acid as linker to form hetero-structure.The phase purity and crystallinity of CdSe quantum dots and $\mathrm{PbTiO}_{3}$ are examined using $\mathrm{X}$-ray diffraction analysis and the morphologies are studied using field emission scanning electron microscopy (FESEM) and transition electron microscopy (TEM) techniques. The optical properties are examined using UV-visible spectroscopy and the band gap of quantum dots and perovskite are derived. The XRD analysis of CdSe quantum dots revealed the high crystallinity with a cubic phase and tetragonal phase for $\mathrm{PbTiO}_{3}$. The surface morphological observations demonstrate that $\mathrm{PbTiO}_{3}$ size in the range of $80-120 \mathrm{~nm}$ in size. The TEM analysis revealed the single crystalline nature for $\mathrm{PbTiO}_{3}$ nanoparticles. The optical band gap of $\mathrm{PbTiO}_{3}$ is found to be 3.7 and $2.25 \mathrm{eV}$ for CdSe quantum dots. The CdSe quantum dots sensitized $\mathrm{PbTiO}_{3}$ hetero-structure's photo-electrochemical water splitting behaviour is examined in $1 \mathrm{M} \mathrm{Na}_{2} \mathrm{~S}$ electrolyte under $100 \mathrm{~mW} / \mathrm{cm}^{2}$ light illumination. As photoanode, CdSe quantum dots sensitized $\mathrm{PbTiO}_{3}$ heterostructure demonstrated $63 \mathrm{~mA} / \mathrm{cm}^{2}$ under illumination and 51 $\mathrm{mA} / \mathrm{cm}^{2}$ dark at $0.8 \mathrm{~V}\left(v s . \mathrm{Ag} / \mathrm{AgCl}\right.$ ), which implies that photocurrent density of $12 \mathrm{~mA} / \mathrm{cm}^{2}$ at $0.8 \mathrm{~V}(v s . \mathrm{Ag} / \mathrm{AgCl})$ and also showed 1.2 $\mathrm{mmol} / \mathrm{g}$ of $\mathrm{H}_{2}$ evolution during the period of $4 \mathrm{~h}$ in chrono-amperometry studies at $0.8 \mathrm{~V}(\mathrm{vs}$. Ag/AgCl). This work discusses the significance and novelty of the usage of $\mathrm{CdSe}$ quantum dots sensitized $\mathrm{PbTiO}_{3}$ heterostructureas photo-electrocatalyst and paves pathway for newer materials development for enhanced photo-electrochemical water splitting.
\end{abstract}

Keywords: CdSe Quantum dots, $\mathrm{PbTiO}_{3}$ perovskites, Nanoparticles, photo-electrochemical water splitting.

\section{INTRODUCTION}

The development of stable catalyst for semiconductor based photocatalysis of water, to produce clean futuristic fuel hydrogen, is gaining more importance in the field of material science research and development $[1,2]$. Since the first report on photoelectrochemical water splitting using $\mathrm{TiO}_{2}$ semiconductor, reported by Fujishima and Honda in 1972 [3], major efforts have been undertaken by many researchers to develop photoactive semiconductors, which can split water into oxygen and hydrogen with and without bias potentials. Typically, semiconductor based metal oxides, such as $\mathrm{TiO}_{2}, \mathrm{WO}_{3}, \mathrm{ZnO}$ and $\mathrm{SnO}_{2}$ were explored as photocatalyst in the solar water electrolysis [4-7]. Nevertheless, the photo-electrochemical water splitting behaviour of these oxides do have limitations because of inade- quate visible absorption and also not have negative conduction band (CB) which favours $\mathrm{H}_{2}$ evolution reaction. Enhanced photocatalytic water splitting efficiency can be realized with the use of visible light absorbing semiconductors, as the solar spectrum consists of almost $50 \%$ visible light $(400<\lambda<800 \mathrm{~nm})$. In this regard, visible light sensitive quantum dots gained more importance, to be as candidate materials in photoelectrochemical water splitting, due to higher band absorption coefficients [8]. However, due to the small band gap, recombination of photogenerated electrons takes part, which is not beneficial for solar water splitting. Hence, the formation of hetero-structures, where narrow band gap quantum dots are sensitized on large band gap semiconductors linked either chemically or physically, is prioritized in photo-electrochemical water splitting [9-14]. To highlight, several heterostructures have been developed using

This is an open access journal, and articles are distributed under the terms of the Creative Commons Attribution-NonCommercial 4.0 International (CC BY-NC 4.0) License, which allows others to copy and redistribute the material in any medium or format, remix, transform, and build upon the material, as long as appropriate credit is given and the new creations are licensed under the identical terms. 
CdSe quantum dots such as $\mathrm{CdSe} / \mathrm{TiO}_{2}, \mathrm{CdSe} / \mathrm{CdS} / \mathrm{TiO}_{2}, \mathrm{CdS} /$ $\mathrm{CdSe} / \mathrm{ZnO}, \mathrm{CdSe} / \mathrm{CdS} / \mathrm{ZnO}, \mathrm{CdSe} / \mathrm{ZnS} / \mathrm{ZnO}, \mathrm{CdSe} / \mathrm{SiNWs}$ and $\mathrm{CdS} / \mathrm{CdSe} / \mathrm{ZnO} / \mathrm{TiO}_{2}$ emphasizing the role of band gap alignment in efficient water splitting [15-21]. Most recent works emphasize that perovskites having $\mathrm{ABO}_{3}$ formula, are being identified as one of the most suitable materials in energy conversion devicesdue to its unique electronic band structure and unidirectional charge transfer properties. To highlight, $\mathrm{SrTiO}_{3}$ perovskite-based oxide with a wide band gap of $3.4 \mathrm{eV}$, explored as photocatalyst in solar water splitting and in addition to this, the heterostructures, $\mathrm{CdSe}$ QDs/ $/ \mathrm{SrTiO}_{3}$ and $\mathrm{NiO} / \mathrm{SrTiO}_{3}$ structures were also being studies [22,23].

Recently, $\mathrm{PbTiO}_{3}$ perovskite oxide is gaining more importance in the research due to the superior properties like ferroelectricity, piezoelectricity and magnetoresistivity [24-28]. The $\mathrm{PbTiO}_{3}$ perovskite is $\mathrm{d}(0)$ and $\mathrm{d}(10)$ metal oxide with ferroelectric polarization and demonstrated as excellent photocatalyst in organic dyes degradation and photocatalytic hydrogen generation [29-31]. The $\mathrm{PbTiO}_{3}$ perovskite based heterostructure are also being fabricated and explored as photo electrocatalyst in water splitting. To highlight, Won Ahn et al. [32] developed $\mathrm{Pt}$ nanodot deposited $\mathrm{PbTiO}_{3}$ and demonstrated effective charge separation with higher photocurrent density in photoelectrochemical water splitting. Jang et al. [33] fabricated core-shell $\mathrm{PbTiO}_{3} @ \mathrm{TiO}_{2}$ heterojunction nanotube array and showed excellent photoelectrochemical water splitting. Liu et al. [34] constructed $\mathrm{TiO}_{2}$ islands on ferroelectric $\mathrm{PbTiO}_{3}$ crystals and demonstrated enhanced photocatalytic hydrogen generation in both UV and visible light irradiation. Inspite of the above reported works, surprisingly, photoelectrochemical water splitting acivity of $\mathrm{CdSe}$ quantum dots sensitized $\mathrm{PbTiO}_{3}$ heterostructure have not been studies well. In this regard, we have focussed on using $\mathrm{CdSe}$ quantum dots sensitized $\mathrm{PbTiO}_{3}$ heterostructure in photo-electrochemical water splitting behaviour and examined photoelectrochemical hydrogen generation activity in this work.

The present work describes the fabrication of $\mathrm{CdSe}$ quantum dots sensitized $\mathrm{PbTiO}_{3}$ heterostructure and explored as photocatalyst in photo-electrochemical water splitting in $1 \mathrm{M} \mathrm{Na}_{2} \mathrm{~S}$ electrolyte under $100 \mathrm{~mW} / \mathrm{cm}^{2}$ light illumination. As photoanode, $\mathrm{CdSe}$ quantum dots sensitized $\mathrm{PbTiO}_{3}$ heterostructure demonstrated $63 \mathrm{~mA} / \mathrm{cm} 2$ under illumination and $51 \mathrm{~mA} / \mathrm{cm}^{2}$ in dark at $0.8 \mathrm{~V}(v s . \mathrm{Ag} / \mathrm{AgCl})$, which implies that photocurrent density of $12 \mathrm{~mA} / \mathrm{cm}^{2}$ at $0.8 \mathrm{~V}(v s . \mathrm{Ag} / \mathrm{AgCl})$ and also showed $1.2 \mathrm{mmol} / \mathrm{g}$ of $\mathrm{H}_{2}$ evolution during the period of $4 \mathrm{~h}$ in chronoamperometry studies at $0.8 \mathrm{~V}(v s . \mathrm{Ag} / \mathrm{AgCl})$. This work discusses the significance and novelty of the usage of CdSe quantum dots sensitized $\mathrm{PbTiO}_{3}$ heterostructure as photo-electrocatalyst and paves pathway for newer materials development for enhanced photo-electrochemical water splitting.

\section{EXPERIMENTAL}

Synthesis of $\mathrm{PbTiO}_{3}: \mathrm{PbTiO}_{3}$ nanoparticles were synthesized via hydrothermal route. Lead nitrate $(10 \mathrm{mmol})$ and $\mathrm{TiCl}_{4}$ dissolved separately in distilled water and mixed together with constant stirring. Further, $10 \mathrm{~mol} \mathrm{NaOH}$ solution was added to the above solution and transferred into a $50 \mathrm{~mL}$ capacity Teflon-lined stainless-steel autoclave. The reaction temperature was maintained at $170{ }^{\circ} \mathrm{C}$ for the period of $8 \mathrm{~h}$ and cooled to room temperature. The resulted product was washed several times using ethanol-water and dried at $120^{\circ} \mathrm{C}$ for $15 \mathrm{~min}$.

Synthesis of CdSe quantum dots: The CdSe quantum dots were synthesized according to the reported work [35]. In a typical synthesis using three-neck flask, $0.3 \mathrm{mmol}$ of cadmium oxide mixed with $0.6 \mathrm{~g}$ of oleic acid were heated to $180^{\circ} \mathrm{C}$ until a clear solution formed and cooled down to room temperature. 1-Hexadecylamine $(4 \mathrm{~mL})$ and tri- $n$-octylphosphine oxide $(7 \mathrm{~mL})$ were added to the mixture and heated to $100{ }^{\circ} \mathrm{C}$ for $10 \mathrm{~min}$. To this solution, tri- $n$-octylphosphine $(1$ $\mathrm{mL}$ ) containing selenium was gently injected and allowed for crystal growth at $280^{\circ} \mathrm{C}$. Further, $1 \mathrm{~mL}$ of CdSe quantum dots were washed with methanol solvent by centrifugation at 3000 $\mathrm{rpm}$ and stored in toluene. In this, $1 \mathrm{~mL}$ of solution were mixed with $1 \mathrm{~mL}$ of acetone and $1 \mathrm{~mL}$ of 3-mercaptopropionic acid (MPA) and the formed 3-mercaptopropionic acid capped CdSe quantum dots was washed and stored in de-ionized water.

Sensitization of CdSe quantum dots on $\mathrm{PbTiO}_{3}$ : The 3 -mercaptopropionic acid capped CdSe quantum dots $(10 \mathrm{mg})$ was mixed with $20 \mathrm{mg}$ of $\mathrm{PbTiO}_{3}$ powder and stirred for $4 \mathrm{~h}$ to form $\mathrm{CdSe}$ quantum dots sensitized $\mathrm{PbTiO}_{3}$ heterostructure. The resulted powder applied as paste on conducting glass and dried at $60^{\circ} \mathrm{C}$ and explored as photoanodes in photoelectro-chemical studies.

\section{RESULTS AND DISCUSSION}

X-ray diffraction analysis: The phase purity and crystallinity of CdSe sensitised $\mathrm{PbTiO}_{3}$ perovskite are examined using X-Ray diffraction (Bruker-Advanced D8) analysis. Fig. 1 shows high crystallinity for $\mathrm{CdSe}$ sensitised $\mathrm{PbTiO}_{3}$ perovskite. The peaks for CdSe quantum dots are well matched with standard JCPDS file no. \# 19-0191 and demonstrate the cubic phase, where $\mathrm{a}=\mathrm{b}=\mathrm{c}=6.07 \AA$ and belongs to F-43m space group [15-21]. The broadened peaks at $24.9^{\circ}$ corresponds to (111) plane of CdSe quantum dots and rest of the peaks at $42^{\circ}$ and $49.7^{\circ}$ correspond to (220) and (311) planes, respectively.

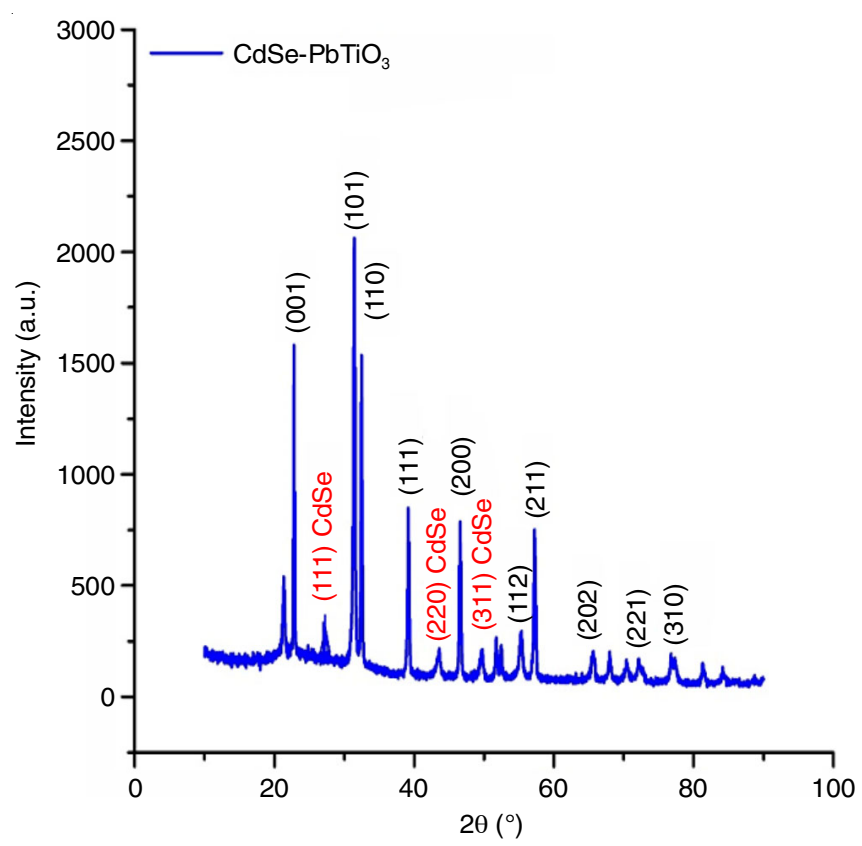

Fig. 1. X-ray diffraction pattern for $\mathrm{CdSe}$ sensitised $\mathrm{PbTiO}_{3}$ perovskite 
The major peak $31.4^{\circ}$ corresponds to (101) plane with interplanar distance (d) of $0.28 \mathrm{~nm}$ and other major peaks at $24.6^{\circ}$ and $32.4^{\circ}$ corresponds to (001) and (110) planes respectively, demonstrates the high crystallinity with tetragonal phase for $\mathrm{PbTiO}_{3}$ perovskite. All the obtained peaks are well matched with standard JCPDS file no. \# 78-0298. The XRD result revealed that the $\mathrm{CdSe}$ quantum dots are functionalized with $\mathrm{PbTiO}_{3}$ perovskite and formed as heterostructure.

UV-visible spectra: The UV-visible spectra recorded using (Speccord 200 Plus, 200-800 nm). UV-visible spectra of $\mathrm{PbTiO}_{3}$ perovskite and $\mathrm{CdSe}$ sensitised $\mathrm{PbTiO}_{3}$ perovskite are shown in Fig. 2. The UV-visible spectrum of $\mathrm{PbTiO}_{3}$ perovskite shows the absorption at $335 \mathrm{~nm}$ wavelength indicating the band gap of $3.7 \mathrm{eV}$. The CdSe sensitized CdSe sensitized $\mathrm{PbTiO}_{3}$ perovskite demonstrated the absorbance at $550 \mathrm{~nm}$ wavelength, which indicate the band gap $2.25 \mathrm{eV}$ attributed to the presence of CdSe quantum dots. This behaviour clearly indicates that the formation of heterostructure.

Surface morphological analysis: The surface morphologies of $\mathrm{CdSe}$ sensitized $\mathrm{PbTiO}_{3}$ and are shown in Fig. 3a-b. The FESEM images of $\mathrm{CdSe}$ sensitized $\mathrm{PbTiO}_{3}$ perovskite is shown in Fig. 3c-d. It is seen that irregular shaped nanoparticles for CdSe sensitized $\mathrm{PbTiO}_{3}$ and $\mathrm{CdSe}$ sensitized $\mathrm{PbTiO}_{3}$ perovskite is shown that $\mathrm{CdSe}$ quantum dots presence over $\mathrm{PbTiO}_{3}$ nanoparticles.

TEM images of $\mathrm{PbTiO}_{3}$ nanoparticles and $\mathrm{CdSe}$ sensitized $\mathrm{PbTiO}_{3}$ perovskites are shown in Fig. 4 (using TEM, Technai

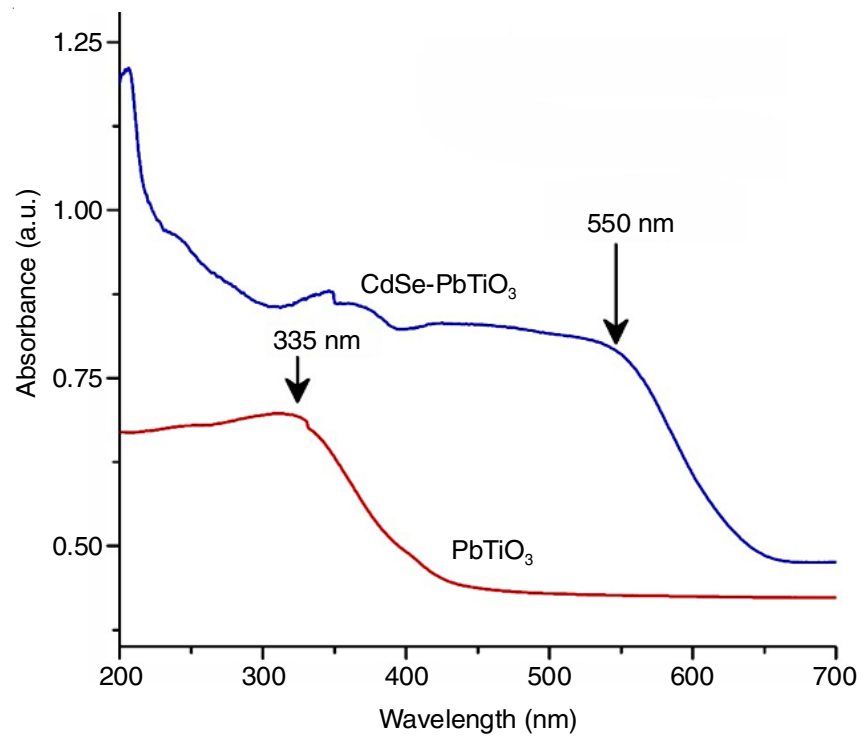

Fig. 2. UV-visible absorbance spectra of $\mathrm{PbTiO}_{3}$ and $\mathrm{CdSe}$ sensitised $\mathrm{PbTiO}_{3}$ perovskite

G2 20).The TEM images of $\mathrm{PbTiO}_{3}$ perovskite nanoparticles are shown in Fig. 4a-b indicate the irregular shaped nanoparticles. Fig. $4 \mathrm{c}$ shows the morphology of $\mathrm{CdSe}$ sensitized $\mathrm{PbTiO}_{3}$ perovskite and it can be seen that the smallest nanoparticles (CdSe quantum dots) covered over larger nanoparticles of $\mathrm{PbTiO}_{3}$. Fig. $4 \mathrm{c}$ revealed that polycrystalline CdSe quantum dots are mixed with single crystalline $\mathrm{PbTiO}_{3}$ nanoparticles.
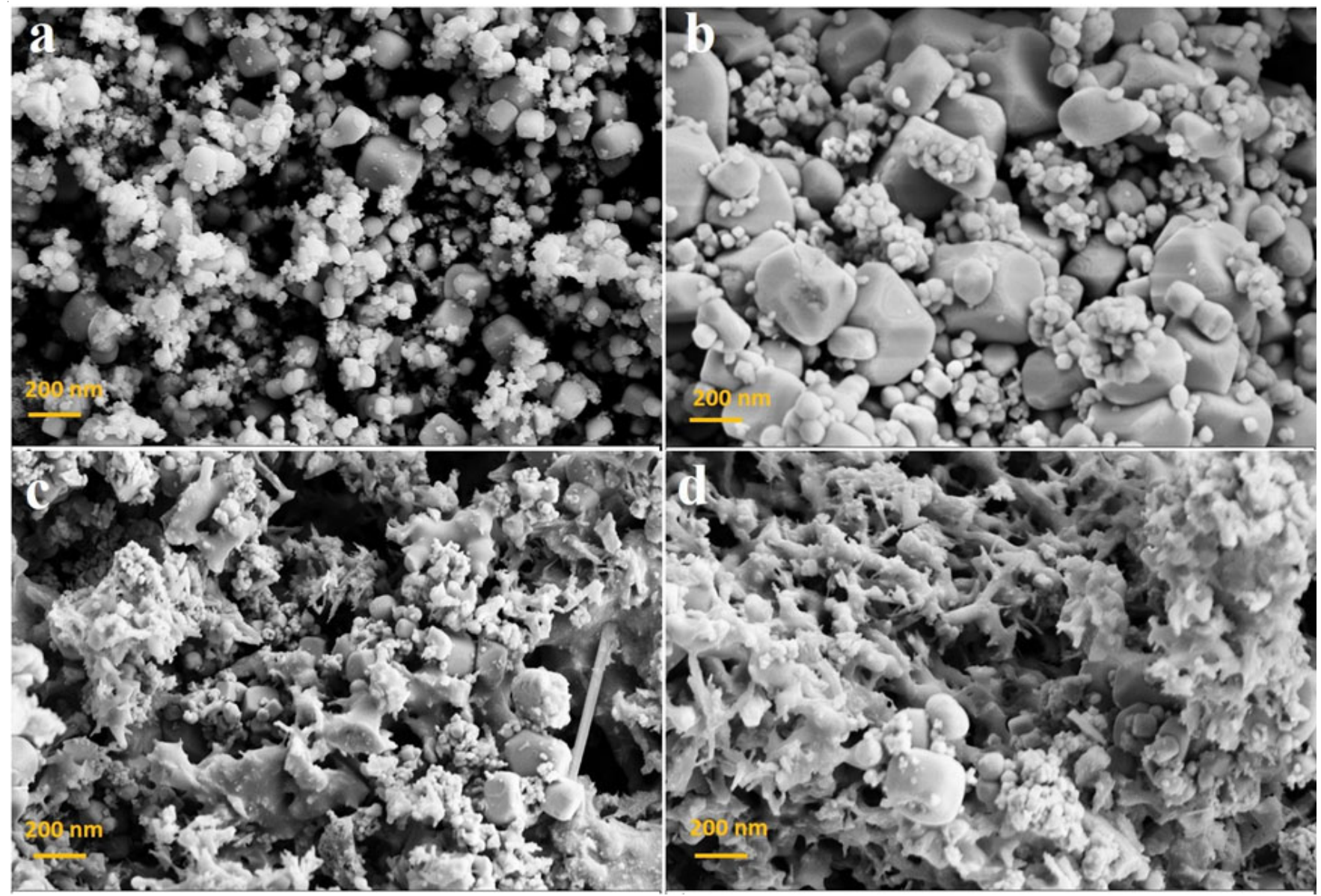

Fig. 3. FESEM images of (a \& b) $\mathrm{PbTiO}_{3}$ and (c \& d) CdSe sensitised $\mathrm{PbTiO}_{3}$ perovskite 

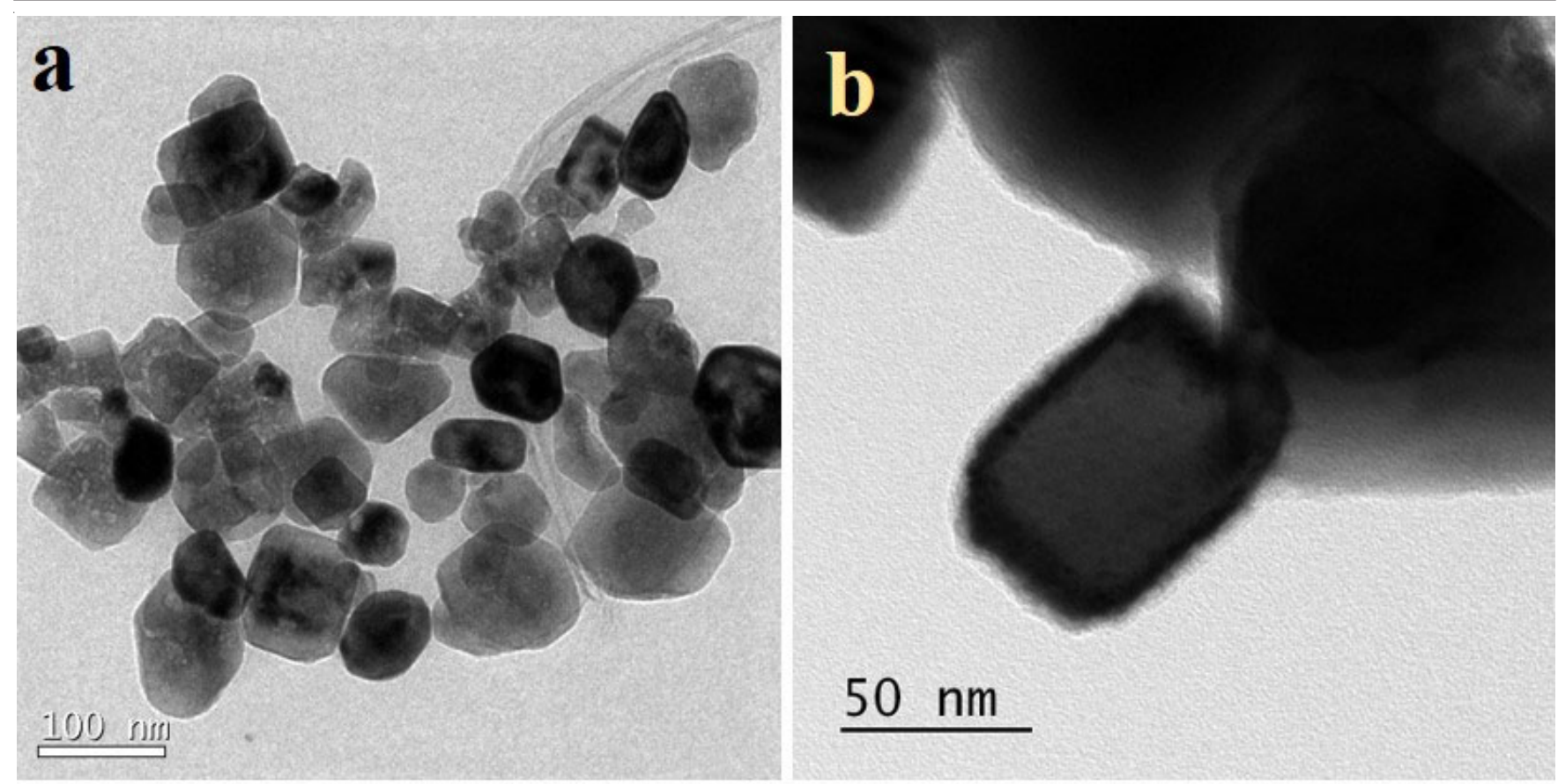

\section{$50 \mathrm{~nm}$}
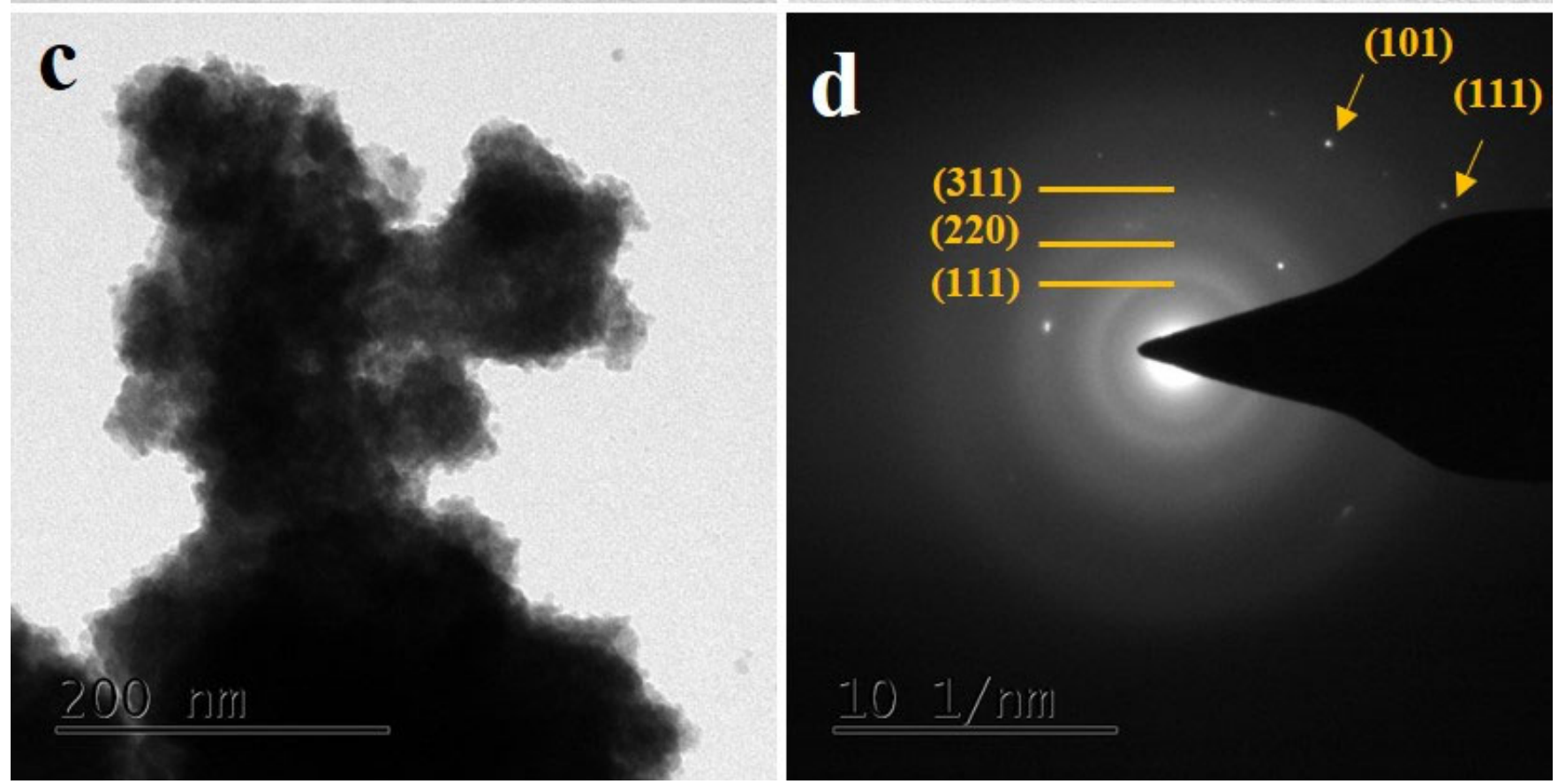

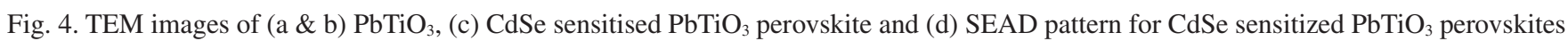

Photo-electrochemical water splitting: The CdSe quantum dots sensitized $\mathrm{PbTiO}_{3}$ perovskite photoanode generate electrons under UV-visible light illumination. The $\mathrm{PbTiO}_{3}$ showed large band gap of $3.7 \mathrm{eV}$, where incident photon energy to excite the electrons from valance band to conduction band of $\mathrm{PbTiO}_{3}$, requires more energy and also a limited UV region absorption of $\mathrm{PbTiO}_{3}$ perovskite makes inefficient to act as photocatalyst in solar water splitting. However, use of narrow band gap cocatalyst, sensitized over large band gap, makes the heterostructure, which may have expected to perform the superior solar water splitting activity. In this regard, CdSe quantum dots sensitized $\mathrm{PbTiO}_{3}$ heterostructure is fabricated and the electron transfer mechanism with band structure analysis is shown in Fig. 5. The photogenerated electrons in $\mathrm{CdSe}$ quantum dots are transferred to the charge band of $\mathrm{PbTiO}_{3}$, then further transferred to the platinum foil (counter electrode) where protons are reduced and favours the $\mathrm{H}_{2}$ generation. Simultaneously, the holes move to the photoanode/electrolyte interface and are collected by hole scavengers $\left(\mathrm{S}_{2}^{-}\right)$.

Photoelectrochemical water splitting behaviour analyzed in three electrode systems using Bio-Logic, Model: VMP3 and EC-Lab software, version 10.31, the exposure area of working electrode was illuminated with a solar-simulated light source (power intensity of $100 \mathrm{~mW} / \mathrm{cm}^{2}$ from $300 \mathrm{~W}$ Xe lamp passing through an AM 1.5G filter Model-SS80AA).

The prepared photoanodes of CdSe quantum dots sensitized $\mathrm{PbTiO}_{3}$ perovskite heterostructure were used as working electrodes in an aqueous solution of $1 \mathrm{M} \mathrm{Na}_{2} \mathrm{~S}, 0.1 \mathrm{M} \mathrm{Na}_{2} \mathrm{SO}_{3}$ 


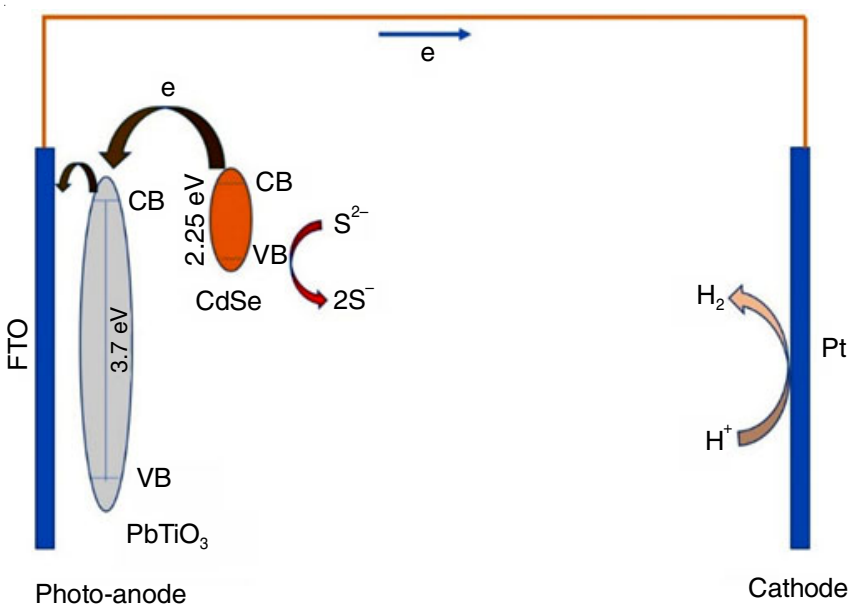

Fig. 5. Band gap structure of $\mathrm{CdSe}$ sensitised $\mathrm{PbTiO}_{3}$ perovskite heterostructure

and $1 \mathrm{M} \mathrm{KOH}$ electrolytes. Fig. 6a illustrates linear sweep voltammograms of $\mathrm{CdSe}$ sensitized $\mathrm{PbTiO}_{3}$ perovskite heterostructure in $1 \mathrm{M} \mathrm{Na}_{2} \mathrm{~S}$ electrolyte under light and dark conditions. The onset potential of oxygen evolution reaction starts at -0.4 $\mathrm{V}$ in dark and shifted to $-0.5 \mathrm{~V}$ in light condition. The current density obtained is 51 and $63 \mathrm{~mA} / \mathrm{cm}^{2}$ in dark and light condition at $0.8 \mathrm{~V}(v s . \mathrm{Ag} / \mathrm{AgCl})$, indicates that the photocurrent density is about $12 \mathrm{~mA} / \mathrm{cm}^{2}$.
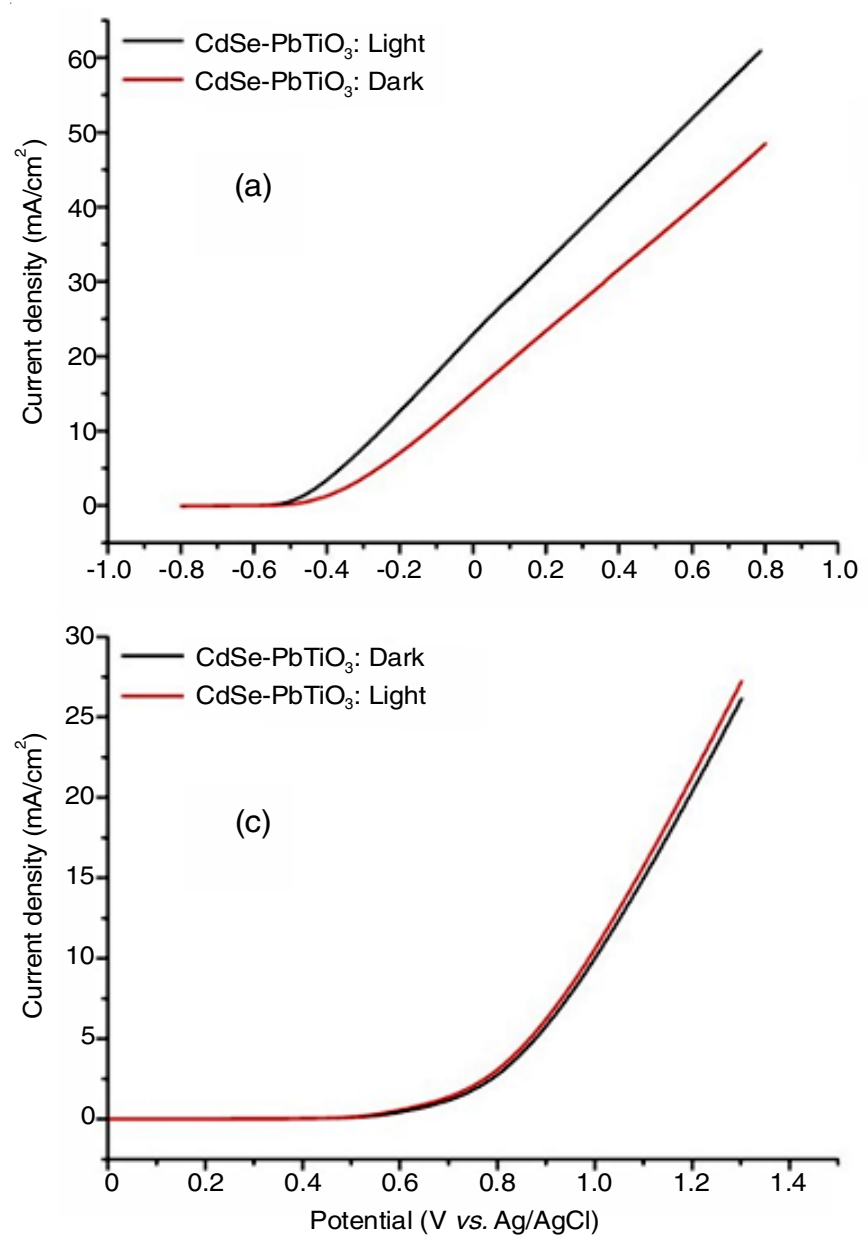

Fig. 6b illustrates linear sweep voltammograms of CdSe sensitized $\mathrm{PbTiO}_{3}$ perovskite heterostructure in $1 \mathrm{M} \mathrm{KOH}$ electrolyte under light and dark conditions. The current density obtained is 6.7 and $9 \mathrm{~mA} / \mathrm{cm}^{2}$ in dark and light condition at $0.8 \mathrm{~V}$ ( vs. $\mathrm{Ag} / \mathrm{AgCl}$ ), indicates that the photocurrent density is about $2.3 \mathrm{~mA} / \mathrm{cm}^{2}$. Fig. 6c illustrates linear sweep voltammograms of CdSe sensitized $\mathrm{PbTiO}_{3}$ perovskite heterostructure in $0.1 \mathrm{M} \mathrm{Na}_{2} \mathrm{SO}_{3}$ electrolyte under light and dark conditions. The current density obtained is 26.5 and $28 \mathrm{~mA} / \mathrm{cm}^{2}$ in dark and light condition at $0.8 \mathrm{~V}$ ( vs. $\mathrm{Ag} / \mathrm{AgCl})$, indicates that the photocurrent density is about $1.5 \mathrm{~mA} / \mathrm{cm}^{2}$. Fig. $6 \mathrm{~d}$ shows the amount of hydrogen evolved during $4 \mathrm{~h}$ chrono-amperometric studies on CdSe quantum dots sensitized $\mathrm{PbTiO}_{3}$ perovskite at $0.8 \mathrm{~V}$ (vs. $\mathrm{Ag} / \mathrm{AgCl}$ ) in $1 \mathrm{M} \mathrm{Na}_{2} \mathrm{~S}$ electrolyte under dark and illumination condition. In dark, nearly $0.6 \mathrm{mmol}$ of $\mathrm{H}_{2}$ is evolved, while in light, $1.3 \mathrm{mmol}$ is generated per gram of CdSe quantum dots sensitized $\mathrm{PbTiO}_{3}$ perovskite. The LSV curves of $\mathrm{CdSe}$ quantum dots sensitized $\mathrm{PbTiO}_{3}$ perovskite in all the three electrolytes demonstrated appreciable photoactivity. It is worth to compare the current work results with the reported catalysts. Sreedhar et al. [36] fabricated CdSe quantum dots sensitized $\mathrm{SrTiO}_{3}$ perovskite and explored as photocatalyst in $1 \mathrm{M} \mathrm{Na}_{2} \mathrm{~S}$ electrolyte. The authors demonstrate $2 \mathrm{~mA} / \mathrm{cm}^{2}$ photocurrent density at $0.8 \mathrm{~V}$ (vs. $\mathrm{Ag} / \mathrm{AgCl})$. Similarly, Wang et al. [37] fabricated carbon quantum dots sensitized $\mathrm{SrTiO}_{3}$ and showed $0.5 \mathrm{~mA} /$
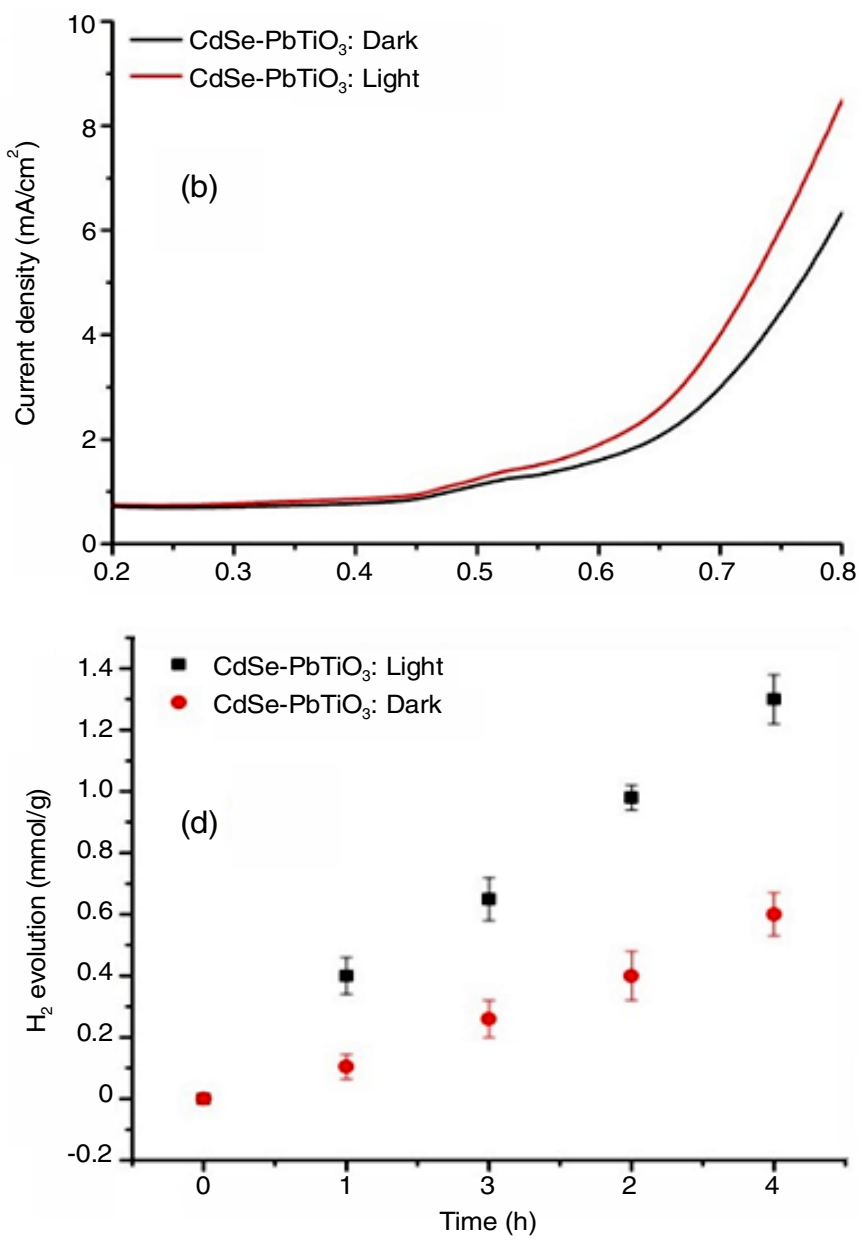

Fig. 6. Linear sweep voltammograms of CdSe QDs sensitized $\mathrm{PbTiO}_{3}$ perovskite in (a) $1 \mathrm{M} \mathrm{Na}_{2} \mathrm{~S}$ electrolyte (b) $1 \mathrm{M}$ KOH electrolyte (c) 0.1 $\mathrm{M} \mathrm{Na}_{2} \mathrm{SO}_{3}$ electrolyte and (d) amount of hydrogen evolution using CdSe QDs sensitized $\mathrm{PbTiO}_{3}$ in $1 \mathrm{M} \mathrm{Na}_{2} \mathrm{~S}$ electrolyte for the period of $4 \mathrm{~h}$ at $0.8 \mathrm{~V}(\mathrm{vs} . \mathrm{Ag} / \mathrm{AgCl})$ 
$\mathrm{cm}^{2}$ photocurrent density in $0.1 \mathrm{M} \mathrm{Na}_{2} \mathrm{SO}_{4}$ electrolyte. Yang et al. [38] fabricated $\mathrm{TiO}_{2} / \mathrm{BaTiO}_{3}$ core-shell heterostructure and demonstrated $0.6 \mathrm{~mA} / \mathrm{cm}^{2}$ in $1 \mathrm{M} \mathrm{NaOH}$ electrolyte. The photocurrents obtained in the current work is higher than the reported results. This could be achieved via strong absorption band edge of $\mathrm{CdSe}$ quantum dots and effective utilization of photogenerated electrons using $\mathrm{PbTiO}_{3}$ perovskite heterostructure. Won-Ahn et al. [32] developed platinum nanodot deposited $\mathrm{PbTiO}_{3}$ heterostructure for effective charge separation for enhanced photoelectrochemical water splitting and showed 60 $\mu \mathrm{A} / \mathrm{cm}^{2}$ photocurrent density in $1 \mathrm{M} \mathrm{KOH}$ solution, which is lower than that in comparison with CdSe quantum dots sensitized $\mathrm{PbTiO}_{3}$ photocatalyst in $1 \mathrm{M} \mathrm{KOH}$ electrolyte, where we demonstrated $1.5 \mathrm{~mA} / \mathrm{cm}^{2}$ at $0.8 \mathrm{~V}(v s . \mathrm{Ag} / \mathrm{AgCl})$.

\section{Conclusion}

We have synthesized and fabricated CdSe quantum dots sensitized $\mathrm{PbTiO}_{3}$ perovskite-heterostructure and explored as photoelectrocatalyst in $\mathrm{Na}_{2} \mathrm{~S}, \mathrm{Na}_{2} \mathrm{SO}_{3}$ and $\mathrm{KOH}$ electrolytes. Higher photo current density of $\sim 12 \mathrm{~mA} / \mathrm{cm}^{2}$ was drawn CdSe quantum dots sensitized $\mathrm{PbTiO}_{3}$ perovskite-heterostructure in a sacrificial $1 \mathrm{M} \mathrm{Na}_{2} \mathrm{~S}$ aqueous solution at $0.8 \mathrm{~V}$ (vs. $\left.\mathrm{Ag} / \mathrm{AgCl}\right)$, whereas 2.3 and $1.5 \mathrm{~mA} / \mathrm{cm}^{2}$ obtained in $1 \mathrm{M} \mathrm{KOH}$ and $0.1 \mathrm{M}$ $\mathrm{Na}_{2} \mathrm{SO}_{3}$ electrolytes, respectively. It is anticipated that this new approach for the fabrication of CdSe quantum dots sensitized $\mathrm{PbTiO}_{3}$ perovskite-heterostructure for high efficiency perovskite solar energy conversion and hydrogen generation devices.

\section{CONFLICT OF INTEREST}

The authors declare that there is no conflict of interests regarding the publication of this article.

\section{REFERENCES}

1. X. Li, J. Yu, J. Low, Y. Fang, J. Xiao and X. Chen, J. Mater. Chem. A Mater. Energy Sustain., 3, 2485 (2015); https://doi.org/10.1039/C4TA04461D

2. M.G. Walter, E.L. Warren, J.R. McKone, S.W. Boettcher, Q. Mi, E.A. Santori and N.S. Lewis, Chem. Rev., 110, 6446 (2010); https://doi.org/10.1021/cr1002326.

3. A. Fujishima and K. Honda, Nature, 238, 37 (1972); https://doi.org/10.1038/238037a0.

4. J. Su, L. Guo, N. Bao and C.A. Grimes, Nano Lett., 11, 1928 (2011); https://doi.org/10.1021/nl2000743.

5. S. Hernández, D. Hidalgo, A. Sacco, A. Chiodoni, A. Lamberti, V. Cauda, E. Tresso and G. Saracco, Phys. Chem. Chem. Phys., 17, 7775 (2015); https://doi.org/10.1039/C4CP05857G.

6. F.E. Osterloh, Chem. Soc. Rev., 42, 2294 (2013); https://doi.org/10.1039/C2CS35266D.

7. R. Saito, Y. Miseki and K. Sayama, Chem. Commun., 48, 3833 (2012); https://doi.org/10.1039/c2cc30713h.

8. W.W. Yu, L. Qu, W. Guo and X. Peng, Chem. Mater, 15, 2854 (2003); https://doi.org/10.1021/cm034081k.

9. I. Robel, M. Kuno and P.V. Kamat, J. Am. Chem. Soc., 129, 4136 (2007); https://doi.org/10.1021/ja070099a.

10. S. Chaguetmi, F. Mammeri, S. Nowak, P. Decorse, H. Lecoq, M. Gaceur, J. Ben Naceur, S. Achour, R. Chtourou and S. Ammar, RSC Adv, , 3, 2572 (2013); https://doi.org/10.1039/c2ra21684a.

11. Y. Tak, S.J. Hong, J.S. Lee and K. Yong, Cryst. Growth Des., 9, 2627 (2009); https://doi.org/10.1021/cg801076b.

12. F. Aldeek, C. Mustin, L. Balan, G. Medjahdi, T. Roques-Carmes, P. Arnoux and R. Schneider, Eur. J. Inorg. Chem., 794 (2011); https://doi.org/10.1002/ejic.201000790.
13. F.A. Frame, E.C. Carroll, D.S. Larsen, M. Sarahan, N.D. Browning and F.E. Osterloh, Chem Commun., 2206 (2008); https://doi.org/10.1039/B718796C.

14. A. Kongkanand, K. Tvrdy, K. Takechi, M. Kuno and P.V. Kamat, $J$. Am. Chem. Soc., 130, 4007 (2008); https://doi.org/10.1021/ja0782706.

15. L. Liu, J. Hensel, R.C. Fitzmorris, Y. Li and J.Z. Zhang, J. Phys. Chem. Lett., 1, 155 (2010); https://doi.org/10.1021/jz900122u.

16. M. Seol, H. Kim, W. Kim and K. Yong, Electrochem. Commun., 12, 1416 (2010); https://doi.org/10.1016/j.elecom.2010.07.035.

17. H. Wang, W. Zhu, B. Chong and K. Qin, Int. J. Hydrogen Energy, 39, 90 (2014); https://doi.org/10.1016/j.ijhydene.2013.10.048.

18. G. Wang, X. Yang, F. Qian, J.Z. Zhang and Y. Li, Nano Lett., 10, 1088 (2010); https://doi.org/10.1021/nl100250z.

19. J. Huang, S. Liu, L. Kuang, Y. Zhao, T. Jiang, S. Liu and X. Xu, J. Environ. Sci., 25, 2487 (2013); https://doi.org/10.1016/S1001-0742(12)60330-1.

20. Z. Ali, I. Shakir and D.J. Kang, J. Mater. Chem. A Mater. Energy Sustain., 2, 6474 (2014); https://doi.org/10.1039/C3TA15439D.

21. R.R. Devarapalli, C.K. Kamaja and M.V. Shelke, J. Mater. Chem. A Mater. Energy Sustain., 2, 13352 (2014); https://doi.org/10.1039/C4TA02775B.

22. Z. Jiao, T. Chen, J. Xiong, T. Wang, G. Lu, J. Ye and Y. Bi, Sci. Rep., 3, 2720 (2013); https://doi.org/10.1038/srep02720.

23. L. Etgar, J. Park, C. Barolo, V. Lesnyak, S.K. Panda, P. Quagliotto, S.G. Hickey, M.K. Nazeeruddin, A. Eychmüller, G. Viscardi and M. Grätzel, RSC Adv., 2, 2748 (2012); https://doi.org/10.1039/c2ra20192e.

24. Y. Li, H. Sun, N. Wang, W. Fang and Z. Li, Solid State Sci., 37, 18 (2014); https://doi.org/10.1016/j.solidstatesciences.2014.08.003.

25. A. Yourdkhani and G. Caruntu, J. Phys. Chem. C, 115, 14797 (2011); https://doi.org/10.1021/jp202127t.

26. M. Yashima, K. Omoto, J. Chen, H. Kato and X. Xing, Chem. Mater, 23, 3135 (2011); https://doi.org/10.1021/cm201184y.

27. P. Hu, J. Chen, J. Deng and X. Xing, J. Am. Chem. Soc., 132, 1925 (2010); https://doi.org/10.1021/ja908014u.

28. M. Park, S. Hong, J. Kim, Y. Kim, S. Buhlmann, Y.K. Kim and K. No, Appl. Phys. Lett., 94, 092901 (2009);

https://doi.org/10.1063/1.3081120.

29. D. Arney, T. Watkins and P.A. Maggard, J. Am. Ceram. Soc., 94, 1483 (2011); https://doi.org/10.1111/j.1551-2916.2010.04262.x

30. R. Li, Y. Zhao and C. Li, Faraday Discuss., 198, 463 (2017); https://doi.org/10.1039/C6FD00199H.

31. A. Kakekhani and S. Ismail-Beigi, J. Mater. Chem. A Mater. Energy Sustain., 4, 5235 (2016); https://doi.org/10.1039/C6TA00513F

32. C.W. Ahn, P.H. Borse, J.H. Kim, J.Y. Kim, J.S. Jang, C.-R. Cho, J.-H. Yoon, B. Lee, J.-S. Bae, H.G. Kim and J.S. Lee, Appl. Catal. B, 224, 804 (2018); https://doi.org/10.1016/j.apcatb.2017.11.002.

33. J.S. Jang, C.W. Ahn, S.S. Won, J.H. Kim, W. Choi, B.-S. Lee, J.-H. Yoon, H.G. Kim and J.S. Lee, J. Phys. Chem. C, 121, 15063 (2017); https://doi.org/10.1021/acs.jpcc.7b03081.

34. T.B. Hook, Joule, 2, 1 (2018); https://doi.org/10.1016/j.joule.2017.10.014

35. K. Iwashina and A. Kudo, J. Am. Chem. Soc., 133, 13272 (2011); https://doi.org/10.1021/ja2050315.

36. G. Sreedhar, A. Sivanantham, S. Venkateshwaran, S.K. Panda and M. Eashwar, J. Mater. Chem. A Mater. Energy Sustain., 3, 13476 (2015); https://doi.org/10.1039/C5TA00304K.

37. F. Wang, Y. Liu, Z. Ma, H. Li, Z. Kang and M. Shen, New J. Chem., 37, 290 (2013); https://doi.org/10.1039/C2NJ40988G

38. W. Yang, Y. Yu, M.B. Starr, X. Yin, Z. Li, A. Kvit, S. Wang, P. Zhao, and X. Wang, Nano Lett., 11, 7574 (2015); https://doi.org/10.1021/acs.nanolett.5b03988. 